\title{
Knowledge Management in the Cultivation of Science and Technology Persons
}

\author{
Dan $\mathrm{Bai}^{1, \mathrm{a}}$, Min Zuo ${ }^{2, \mathrm{~b}}$ \\ ${ }^{1}$ Institute of economic management, Dalianuniversity, Dalian, Liaoning, China \\ ${ }^{2}$ Institute of economic management, Dalian university, Dalian, Liaoning, China \\ abaidan@dlu.edu.cn \\ b072013zuomin@163.com
}

Keywords: Knowledge Management. Scientific and Technological Persons.

\begin{abstract}
In the modern enterprise management, knowledge management is a new management philosophy and management style, its unique mode of management plays an important role in the cultivation of science and technology talents. This study, based on building the knowledge management model systemof scientific and technological persons, examinesknowledge management model having important implications to cultivate and improve the science and technology persons' knowledge, abilities and qualities by empirical research methods.
\end{abstract}

\section{Introduction}

With the development of the knowledge economy,the competition for scientific and technological persons is more and more intense and also lead to an increasing demand on scientific and technological persons. The marketing applied scientific and technological persons, having a wealth of knowledge, strong comprehensive ability and high quality get more favor from the employers. In order to meet employers' demand for scientific and technological persons, how to cultivate and develop this scientific and technological persons are faced with the challenges of the modern enterprise management, through the knowledge management theory and practice of learning, we found that the application of knowledge management in the enterprise to develop and enhance their scientific and technological persons' knowledge, ability and quality are beneficial reforms and attempts.

Researching in this area is still very limited, this study combined with knowledge management in the application of enterprise management,makes use of empirical research methods to verify the effect of knowledge management on enterprise scientific and technological persons' knowledge, ability and quality.

\section{Science and Technology Persons Qualities}

American scholars Rahul W.Jackson and RoberD.Hisrich noted that the success of scientific and technical persons have a special quality, the quality of these personnel are not available for the non-success people. They believe that these characteristics into three main areas: quality, skills, knowledge. The quality is the special character of individuals; the skill is professional competence; the knowledge is specialized information ${ }^{[1]}$. Combined with the view of RahulW.Jackson and RoberD.Hisrich, we have the characteristics of scientific and technological personnel as the difference between ordinary unique qualities, qualities here include three aspects: knowledge, ability and quality.

In knowledge, enterprise scientific and technological persons are in addition to master professional knowledge, but also should have anunderstanding of economics, management, law and other aspects. In ability, enterprise scientific and technological persons should have a rich imagination and theoretical generalization capability, innovation, ability to process information gathering, language skills, logical thinking skills, communication skills, self-learning ability, management ability, social skills, and so on ${ }^{[2]}$. In quality, enterprise scientific and technological 
persons should have the force of character, good scientific ethics, honesty and trustworthiness, adaptability, ethics and professionalism, and so on.

\section{Knowledge Management Content and System}

Based on the important role of knowledge management inscientific and technological persons'education, how to develop, access and use knowledge is the key to improving the quality of the scientific and technological persons. Based on this thinking, this paper attempts to apply the idea of enterprise knowledge management intoscientific and technological persons' cultivation, from the view of knowledge management to re-examine training talents, explore effective path of cultivatingtalents.

3.1 Connotation of Knowledge Management. Knowledge managementoriginally produced in the field of management,the famous American managementPeter Dracker proposed the idea of knowledge management, prefigured the coming of knowledge economy which with therevolutionary change of management thinking in the end of 80's. Knowledge will replace capital and labor, competition to becoming the organization's most important strategic resource ${ }^{[3]}$.

The so-called knowledge management is constructed in the organization of both a humanistic and technical knowledge system that allows the organization of information and knowledge, through to get, create, share, integrate, record, access, update and other processes, to achieve the knowledge and innovative the ultimate aim, and back into the knowledge system, knowledge of individuals and organizations all will increase and the knowledge of enterprise will becoming the value of enterprise at the same time ${ }^{[4]}$. It is different from the traditional management model, it's a new management theory and methods, stressed the importance of subjectivity and knowledge of personnel. With this in the enterprise scientific and technological persons is an important carrier of knowledge, during enterprises implement knowledge management model, scientific and technological persons experienced enterprise knowledge management process, which will help to understand and master the knowledge, exercise language skills, communication skills, logical thinking ability capacity and training in all aspects of their own qualities.

3.2 Knowledge Management System. For a comprehensive understanding of knowledge management scholars and combining knowledge of the particularity of culture with the scientific and technological persons, we use a relatively broad sense for the knowledge management in this article, emphasizing the role of knowledge integration with other relevant factors, namely that knowledge management is to obtain, use and innovation knowledge, to promote the survival and development of members of the organization, and to improve the ability to create value.it specifically includes three aspects.

First of all, the knowledge management is a pursuit of value [4].In the level of knowledge, the knowledge management is aimed to the realization of personal goals and organizational values. The mainly meaning is that knowledge management will help improve the level of personal intelligence, realize the vision of organizational knowledge and get directly or indirectly development benefits.

Second, the knowledge management is a dynamic process. From the perspective of knowledge process, knowledge management is on the "knowledge acquisition, application and innovation, which itself is a process of knowledge production, sharing, application and innovation.

Finally, knowledge management is a form of knowledge transformation. From the form of the knowledge level, the focus of knowledge management is to promote the conversion of explicit knowledge and tacit knowledge, and thus to achieve knowledge sharing and application within the organization to promote knowledge innovation organization. From this sense, knowledge management is a form of knowledge management and knowledge of the integration process, so as to promote the realization of the value of knowledge. In summary, knowledge management is to achieve knowledge processes, coordination and balance form of knowledge and knowledge value.

3.4 Knowledge Management Impress Talents' Knowledge, Ability and Quality. The essence of knowledge management is to achieve the balance of knowledge form, knowledge process and knowledge value. Therefore, the basic idea of enterprise scientific and technological personstraining in knowledge management is that through the management of knowledge form and knowledge 
processes, to achieve the improvement of scientific and technological persons' knowledge, ability and quality.

In 1958, the British philosopher Michael Polanyi made the first clear division of two forms of knowledge. On this basis, the Japanese knowledge management exporter Nonakamade the SECI model which proposed explicit knowledge and tacit knowledge conversion ${ }^{[5]}$. The SECI model provides an important inspiration for the understanding of science and technology persons' training. In the training, knowledge plays an irreplaceable role. As a core element of science and technology personnel training, knowledge there is also divided in two forms, explicit knowledge and tacit knowledge. Explicit knowledge, also known as expressly refers to the rules of formal knowledge. It's just part of the technical knowledge that can be transmitted in a certain way. Tacit knowledge means relying on individual experience, intuition and insight, by situational constraints, difficult to regulate and learning.

The explicit knowledge is to answer the questions of "what" and "why". It provided a framework for understanding. Tacit knowledge is mainly from the practice of individual skills, subjective, contextual and practical generative characteristics. In the training of technical personnel, the tacit knowledge is usually in close contact with the explicit knowledge together in practical training in the enterprise, employees with experienced technical personnel to work together to get tacit knowledge, but that knowledge in the process of technical operations and often outside the formal rules of explicit knowledge, thus promoting the formation of individual scientific knowledge and practical ability.

From a process perspective, the flow of knowledge can also be seen as a value added in knowledge process. For the division of knowledge management processes, different institutions and scholars have different views. DibiLa believed that knowledge management processes are: access, dissemination and use: Arthur Anderson business consulting and the American Productivity and Quality Center (APQC) believed that knowledge management processes include: definition, acquisition, adaptation, organization, use, share and create ${ }^{[6]}$. Researchers generally believe that the core process of knowledge management is acquisition and application. Based on the existing theoretical understanding of knowledge management processes, combined with dynamic features of scientific and technological persons training, I will summarize the technical knowledge of the process into four areas: access to technical knowledge, internalization of knowledge,innovation of knowledge and applications of knowledge.

Through the above analysis we can see knowledge management throughout the scientific and technological persons training of the whole process. In order to achieve the goal of high-level scientific and technological person'strainingenterprisecan use knowledge management in this training and the knowledge, ability and quality of scientific and technological persons will improved at the same time for this reason.

\section{Research Design and Date Processing}

In order to verify the knowledge management can cultivate and improve scientific and technological person's knowledge, ability and quality, this study used a questionnaire, conducted a survey on different types of knowledge-intensive enterprises in Dalian and then by the analysis of the questionnaire's results to verify knowledge management having effect on the scientific and technological person's knowledge, ability and quality.

4.1 Questionnaires design. The items of questionnaire mainly get from the results of interviews with students of all ages on the management science and engineering profession and the number is 24. The questionnaire is divided into three parts: the first part (1-3 questions) is the effect of knowledge management on scientific and technological person's knowledge; the second part (4-16 questions) is about knowledge management improves what ability of scientific and technological person; the third part (17-24) is about knowledge management reinforces what aspects of the quality of scientific and technological person. The questionnaire use Likert-5 scale.

4.2 Data collection. The questionnaire primarily knowledge-intensive enterprises in Dalian, population distribution, a total of 260 questionnaires were returned questionnaires 238 points, the 
response rate was $85.33 \%$, of which 229 valid questionnaires, and the effective response rate was 83.33\%.

4.3 Data Analysis. First standardized questionnaire collected data collected, and then making use of SPSS13.0 statistical analysis software analysis the standardized data. Selective principal component analysis, and on maximum variation orthogonal rotation, the retention factor load is greater than the absolute value of 0.5 items, deleting items of cross-factor load, the last remaining 11 items. In accordance with the principle of Eigen values greater than 1 were extracted three factors, the cumulative variance contribution rate is $76.794 \%$, these factors can illustrate the effect of knowledge management on scientific and technological person ' knowledge, ability and quality in the maximum extent.

Through analysis the 11 indicators, the value of Kaiser-Meyer-Olin(KMO) is 0.899, Bartlett's test of sphericity x2 value is 1012.682, so common factors exist in the correlation matrix of the population, that the data is suitable for factor analysis.

The factor analysis on these 11 indicators, and using varimax rotated factor of the orthogonal rotation, after 5 times of rotation after iteration factor load factor as shown in Table 1.

Table 1The OrthogonalRotation Factor Loading Coefficient

\begin{tabular}{|c|c|c|c|c|c|c|}
\hline \multicolumn{4}{|c|}{ Items } & \multicolumn{3}{|c|}{ Factors } \\
\hline No. & Content & Mean & Std.Deviation & 1 & 2 & 3 \\
\hline $\mathrm{X} 1$ & technological innovation capability & 4.2050 & 0.71274 & 0.798 & & \\
\hline $\mathrm{X} 2$ & Ability to process information & 4.2080 & 0.72282 & 0.782 & & \\
\hline X3 & Language skills & 4.2380 & 0.68798 & 0.775 & & \\
\hline $\mathrm{X} 4$ & Social skills & 4.2520 & 0.69826 & 0.692 & & \\
\hline X5 & Logical thinking ability & 4.1460 & 0.73435 & 0.592 & & \\
\hline $\mathrm{X} 6$ & Strong will & 3.8540 & 0.78501 & & 0.825 & \\
\hline X7 & scientific ethics & 3.6140 & 1.00496 & & 0.775 & \\
\hline X8 & $\begin{array}{l}\text { Promote self-motivation and } \\
\text { self-reinforcing }\end{array}$ & 4.2880 & 0.68531 & & 0.756 & \\
\hline X9 & More responsible & 4.1200 & 0.82405 & & 0.732 & \\
\hline $\mathrm{X} 10$ & $\begin{array}{l}\text { the successful transformation of } \\
\text { explicit knowledge }\end{array}$ & 4.246 & 0.64328 & & & 0.898 \\
\hline X11 & $\begin{array}{l}\text { the successful transformation oftacit } \\
\text { knowledge }\end{array}$ & 4.0580 & 0.67566 & & & 0.742 \\
\hline
\end{tabular}

As can be seen from Table 1, the first one factors include X1, X2, X3, X4 and X5 these five indicators, representing the technological innovation capability, the ability to collect process information, language skills, social skills and logical thinking ability, these indicator reflects the impact of knowledge management of the enterprise technology professionals, and the five indicators on the first high load factor; the first two factors include X6, X7, X8 and X9 these four indicators, representing strong willed, scientific ethics, Promote self-motivation and self-reinforcing, more responsible, these indicators reflect the impact of knowledge management on their own quality business technology professionals, and these four indicators in higher load factors on the second; the first three factors including X10 and X11, respectively, on behalf of the successful transformation of explicit knowledge and tacit knowledge of the exact expression, these indicators reflect the impact of knowledge management for enterprise knowledge and technology talent, and these two indicators in the third load factor higher.

The reliability test purpose is to learn more about the 11 indicators and extracted three factors verifying the reliability of effect of experiential teaching on the students' knowledge, ability and quality. 
United States statistician Hair, Anderson, Tyson and Blackburn pointed out that Value greater than 0.7, indicating that the higher reliability of the data, the number of items in the measured foot is less than 6 , the value is greater than 0.6 indicates that the data is reliable ${ }^{[7]}$.

The total scale coefficient obtained by the correlation analysis of the three factors is 0.946 then do each time correlation analysis on three factors obtained after each factor coefficients are 0.911, 0.890 and 0.846 , so the total scale and the reliability coefficients of each factor are shown in Table 2.

Table 2TheTotal Scale and theReliability Coefficients of Each Factor

\begin{tabular}{lllll}
\hline & Total scale & Knowledge & Ability & Quality \\
\hline$\alpha$ Coefficient & 0.946 & 0.911 & 0.890 & 0.846 \\
\hline
\end{tabular}

\section{Conclusion}

In this study, through the empirical analysis of the knowledge management can cultivate and improve the knowledge, ability and quality of scientific and technological persons is verified. Empirical evidence shows that, knowledge management allows scientific and technological persons a deeper understanding and memory of knowledge and mastery of the entire body of knowledge; the knowledge management can improve enterprise talents' communication skills, ability to process information is gathered, language skills, social skills and logical thinking capacity and other aspects of capacity; knowledge management enhance scientific and technological persons' own quality, allow employees to be more honest, more responsible, exercise the will and promote scientific and technological persons' self-motivation and self-reinforcing. Therefore, the results from the study can be seen knowledge management having great influence and effect on cultivate of scientific and technological talents. The advocacy knowledge management mode to cultivate more scientific and technological talents adapt to the development of market economy, the reform is a long way to go.

\section{References}

[1]RapheJackson, Robber D. Hirsch. Sales management [M].China Renaming University Publishers(2001).

[2]Hansen M. T, Nutria T, Tierney T.What's Your Strategy for Managing Knowledge. Harvard Business Review, March-April: 106-116(1999).

[3]Peter F, Drucker. Oxford: Butterworth Heniemann(1993).

[4]Dan Bai, Xin Jin. Socialized Service System Construction of Technological Innovation in China. IEEE CAISSE, June:311-316(2012).

[5]ChoiB, PoonS. K, Davis G. J. Effects of Knowledge Management Strategy on Organizational Performance: A Complementarity Theory-based Approach (2008).

[6]Arthur Andersen Business Consulting and APQC. The Knowledge Management Assessment Tool: External Benchmarking.

[7]Han Xiaoyun, Wang Cunxiao. With service companies Customer Satisfaction and loyalty [M].Tsinghua UniversityPublishers(2003). 